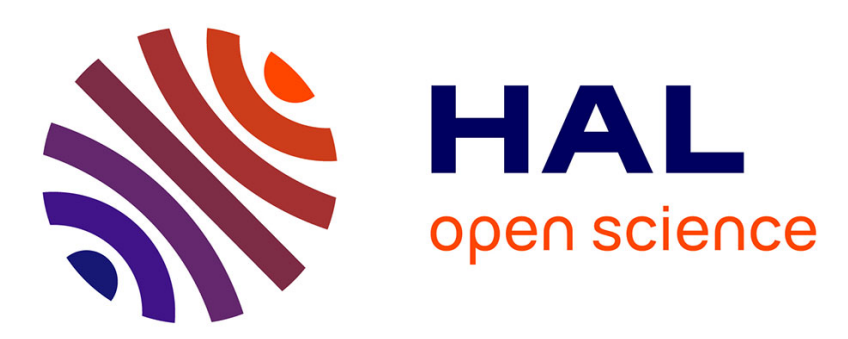

\title{
Interplay between deoxidation and dewetting for ultrathin SOI films
}

\author{
M. Trautmann, F. Cheynis, F. Leroy, S. Curiotto, Pierre Müller
}

\section{To cite this version:}

M. Trautmann, F. Cheynis, F. Leroy, S. Curiotto, Pierre Müller. Interplay between deoxidation and dewetting for ultrathin SOI films. Applied Physics Letters, 2017, 110 (16), pp.161601. 10.1063/1.4980132 . hal-01617080

\section{HAL Id: hal-01617080 \\ https://hal.science/hal-01617080}

Submitted on 4 May 2018

HAL is a multi-disciplinary open access archive for the deposit and dissemination of scientific research documents, whether they are published or not. The documents may come from teaching and research institutions in France or abroad, or from public or private research centers.
L'archive ouverte pluridisciplinaire HAL, est destinée au dépôt et à la diffusion de documents scientifiques de niveau recherche, publiés ou non, émanant des établissements d'enseignement et de recherche français ou étrangers, des laboratoires publics ou privés. 


\section{Interplay between deoxidation and dewetting for ultrathin SOI films}

M. Trautmann, F. Cheynis, F. Leroy, S. Curiotto, and P. Müller

Citation: Appl. Phys. Lett. 110, 161601 (2017); doi: 10.1063/1.4980132

View online: http://dx.doi.org/10.1063/1.4980132

View Table of Contents: http://aip.scitation.org/toc/apl/110/16

Published by the American Institute of Physics

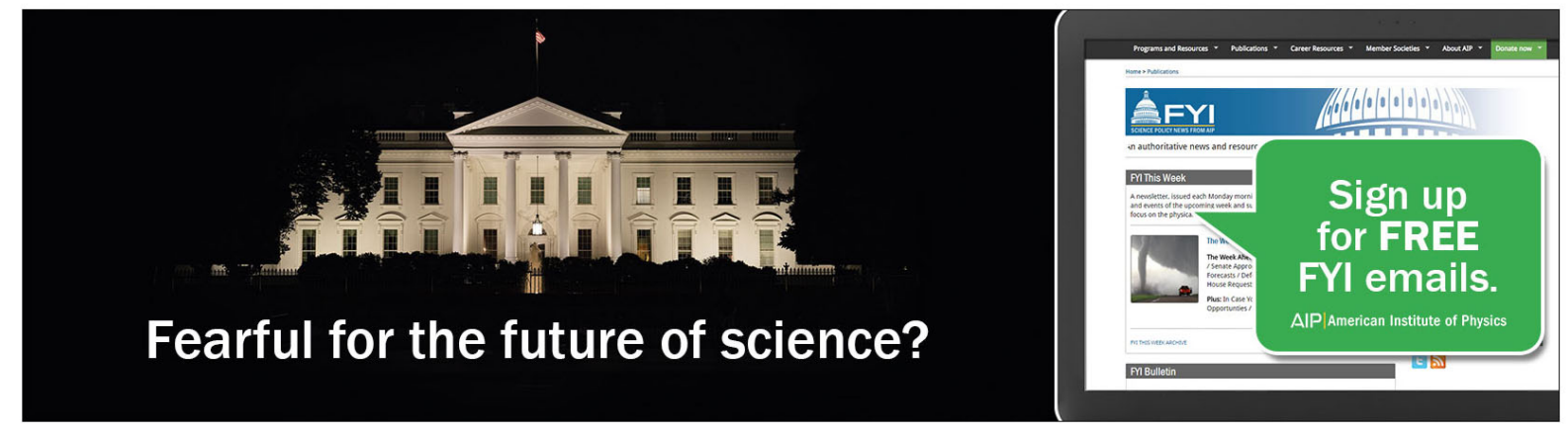




\title{
Interplay between deoxidation and dewetting for ultrathin SOI films
}

\author{
M. Trautmann, F. Cheynis, F. Leroy, S. Curiotto, and P. Müller ${ }^{a)}$ \\ Aix Marseille Univ., CNRS, CINAM, 13288 Marseille Cedex 9, France
}

\author{
(Received 21 February 2017; accepted 3 April 2017; published online 17 April 2017)
}

\begin{abstract}
Solid state dewetting of thin films is a promising method for producing nanodots. However, while films with submicron thicknesses simply breakup into arrays of dots, ultrathin films tend to form more complex dendritic structures. In this paper, we investigate the dewetting properties of ultrathin Silicon-on-Insulator samples capped by a chemically prepared oxide layer. We unambiguously show that the formation of a dendritic structure characteristic of $\operatorname{Si}(100)$ films thinner than $\approx 6 \mathrm{~nm}$ is due to an interplay between deoxidation and dewetting. For thicker films, the deoxidation is observed at lower temperature than the dewetting and thus does not influence the dewetting whereas for the thinner films, both phenomena occur simultaneously. In this case, the dewetted morphology results from the coalescence of voids in the $\mathrm{Si}(100)$ film that are limited by the thermal decomposition of the oxide cap. Published by AIP Publishing. [http://dx.doi.org/10.1063/1.4980132]
\end{abstract}

For the past few years, there have been many efforts for studying solid state dewetting that means the spontaneous agglomeration of a metastable film into an assembly of 3D crystallites. $^{1-3}$ Since the size of the so-formed 3D crystallites depends on the initial thickness of the film, ${ }^{3-6}$ solid state dewetting of ultra-thin films is a promising method for producing nanodots. ${ }^{7-9}$ Many studies thus focused on the effect of the film thickness on the dewetting morphologies. Generally, films with a thickness of $\geq 10 \mathrm{~nm}$ dewet by void nucleation and by opening process producing well-organized 3D islands. ${ }^{1-3}$ In contrast, thinner films tend to form more complex structures. ${ }^{10-15}$ For instance, Kinetic Monte Carlo simulations have shown that a 1 ML-thick film dewets by forming a dendritic pattern of bilayer islands. ${ }^{11,12}$ In the literature, the specific behavior of the thinner films has been attributed to barrierless void nucleation, ${ }^{16}$ spinodal dewetting (enhanced sensitivity to thickness or thermal fluctuations), ${ }^{17}$ short range effect of the wetting potential, ${ }^{18,19}$ or local stresses. ${ }^{15,20}$ Recently, we investigated the dewetting properties of Silicon-on-Insulator (SOI) samples capped by a chemically prepared oxide layer. We thus reported that $\mathrm{Si}(100)$ films thicker than $8 \mathrm{~nm}$ dewet in four steps and break down into self-organized 3D crystals whereas films thinner than $6 \mathrm{~nm}$ dewet by the formation of a dendritic morphology. ${ }^{10}$

In this paper, we show that this thin film effect is actually due to a subtle interplay between film deoxidation and film dewetting. Indeed, the minimum temperature at which a film starts to dewet at a measurable timescale $\left(\mathrm{T}_{\text {dew }}(\mathrm{h})\right.$ ) decreases with its thickness $h$ whereas the deoxidation temperature $\left(\mathrm{T}_{\text {deox }}\right)$ is a constant for all samples; the capping $\mathrm{SiO}_{2}$ layers are prepared according to the same procedure. ${ }^{21}$ We thus show that if $\mathrm{T}_{\text {dew }}(\mathrm{h})>\mathrm{T}_{\text {deox }}$ SOI, dewetting occurs by void opening and leads to self-organized $3 \mathrm{D}$ crystals whereas if $\mathrm{T}_{\text {dew }}(\mathrm{h})<\mathrm{T}_{\text {deox }}$ SOI, dewetting leads to dendritic morphologies. In other words, the dewetting of the thicker films does not depend on the oxide cap that decomposes before dewetting and thus only depends on the surface energy gain due to the disappearance of the Si surface and the film/substrate interface with respect to the uncovered

${ }^{\text {a) }}$ uller@cinam.univ-mrs.fr bare substrate while the dewetting of the thinner films depends on the deoxidation. In the latter case, only the clean and deoxidized parts of the silicon film can dewet.

We use low-energy electron microscopy (LEEM) to investigate in-situ and in real time the decomposition of the oxide and the dewetting of the SOI films in an ultra-high vacuum chamber with a base pressure in the low $10^{-10}$ Torr range. Note that since the reflectivity properties of surfaces depend on the energy of the incident electrons, the contrast between $\mathrm{Si}$ and $\mathrm{SiO}_{2}$ may be inverted according to the value of the electron energy. ${ }^{22,23}$ We define the deoxidation temperature $\mathrm{T}_{\text {deox }}$ as the temperature at which we observe by LEEM void opening in the oxide cap layer with subsequent silicon film appearance. In a similar manner, the dewetting temperature $\mathrm{T}_{\text {dew }}$ is defined as the temperature at which the amorphous $\mathrm{SiO}_{2}$ substrate starts becoming visible by retraction of the silicon film. Obviously, both temperatures $T_{\text {deox }}$ and $T_{\text {dew }}$ do not correspond to phase transitions and thus depend on the observation technique. However, since measured in the same experimental conditions, they can be compared without any ambiguity.

The SOI samples used in the experiments $(12 \mathrm{~nm} \mathrm{Si}$ on top of $25 \mathrm{~nm} \mathrm{SiO}_{2}$ as buried oxide (BOX)) were prepared as described elsewhere. ${ }^{21}$ By means of repeated etching and oxidation cycles, a stepwise thinning of the samples is possible and produces films of a chosen thickness with a very high precision. This procedure ends with a final oxidation step. Since this protective oxide layer is produced with the same wet chemical oxidation for each Si film thickness, the thickness of the oxide is the same for all samples. Ellipsometry measurements have proven that the oxide thickness is constant and approximately equals $1 \mathrm{~nm}$.

In Figure $1, \mathrm{~T}_{\text {deox }}$ and $\mathrm{T}_{\mathrm{dew}}$ are reported as a function of the initial $\mathrm{Si}(100)$ film thickness. As expected, the decomposition temperature of the capping oxide does not depend on the thickness of the silicon film and is rather constant with $\mathrm{T}_{\text {deox }}=760^{\circ} \mathrm{C}$ whereas $\mathrm{T}_{\text {dew }}$ decreases with $\mathrm{h}$ as in Refs. 6 , 24 , and 25 .

In the following, we report the dewetting morphologies recorded in the three observed regimes (1) $\mathrm{T}_{\text {dew }}(\mathrm{h})>\mathrm{T}_{\text {deox }}$ for $\mathrm{h}>6 \mathrm{~nm}$, (2) $\mathrm{T}_{\text {dew }}(\mathrm{h}) \approx \mathrm{T}_{\text {deox }}$ for $6 \mathrm{~nm}>\mathrm{h}>4 \mathrm{~nm}$, and (3) $\mathrm{T}_{\text {dew }}(\mathrm{h})<\mathrm{T}_{\text {deox }}$ for $\mathrm{h}<4 \mathrm{~nm}$. The experimental results 


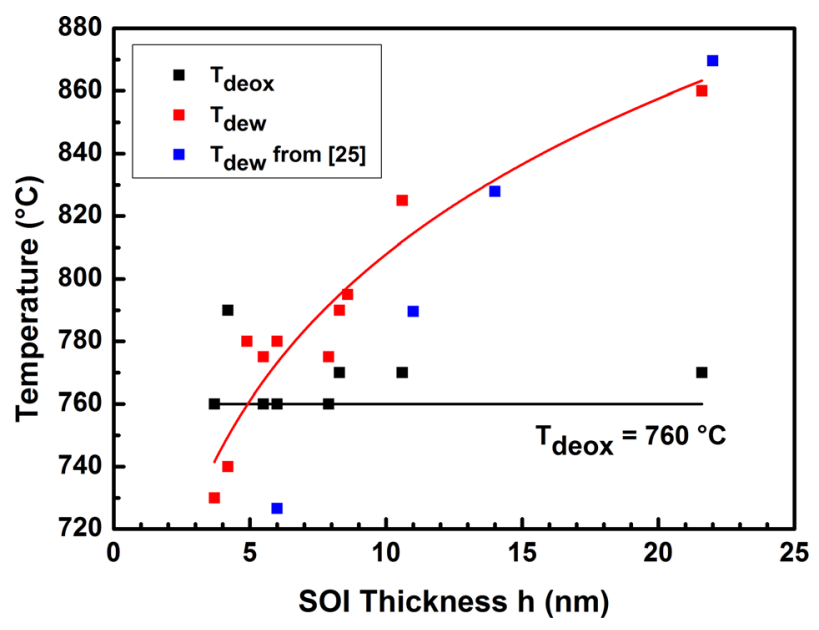

FIG. 1. Temperature at which the initial deoxidation (black) and dewetting (red) are observed as a function of the Si film thickness. Dewetting velocities are in the range of 1 to $8 \mathrm{~nm} / \mathrm{s}$. The data point at $21.6 \mathrm{~nm}$ was obtained using a SOI sample of $22 \mathrm{~nm}$ on top of a $150 \mathrm{~nm} \mathrm{SiO} \mathrm{SOX}_{2}$ BO. The blue data points are obtained from ${ }^{25}$ with a dewetting velocity of $3 \mathrm{~nm} / \mathrm{s}$.

will be then discussed and compared to Kinetic Monte Carlo (KMC) simulations.

For samples with a Si layer thickness above $6 \mathrm{~nm}$, the deoxidation temperature is below the dewetting temperature. This enables to investigate both processes independently without any mutual influence. The deoxidation starts at a temperature of $760^{\circ} \mathrm{C}$ with an arbitrary distribution of circular shaped voids that grow with different velocities (Fig. 2(a)). ${ }^{26}$ Until the deoxidation is finished, the Si film is still stable, and there is no dewetting.

Subsequently, the temperature was slowly increased until the dewetting of the sample was observed. In the case of a Si film of $7.9 \mathrm{~nm}$, the formation of square-shaped voids starts at $775^{\circ} \mathrm{C}$ (Fig. 2(b)). They exhibit edges oriented along the $\langle 110\rangle$ directions and dewetting fingers that break into isolated islands as already described in Refs. 21 and 25 for the dewetting of clean SOI films.

In the case of Si films with a thickness in the range between 4 and $6 \mathrm{~nm}$, the temperatures for deoxidation and dewetting are very close to each other. This means that in the experiment, both processes occur at the same time. As a consequence, a mutual influence can be seen.
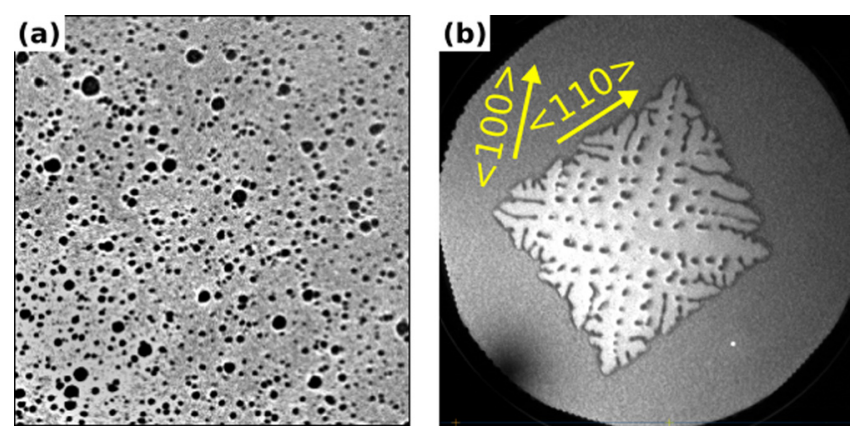

FIG. 2. Annealing of a $\mathrm{Si}$ film with $\mathrm{h}=7.9 \mathrm{~nm}$. (a) Circular deoxidation voids formed at $760^{\circ} \mathrm{C}, \mathrm{Si}$ with dark, $\mathrm{SiO}_{2}$ with bright contrast $\left(E_{e^{-}}=1.1 \mathrm{~V}\right.$, $12 \times 12 \mu \mathrm{m}^{2}$ ). (b) Square-shaped dewetting void formed at $775^{\circ} \mathrm{C}$ and grown faster at $830^{\circ} \mathrm{C}$. Isolated $\mathrm{Si}$ islands are in black, Si film appears in grey, and the BOX surface has a white contrast $\left(E_{e^{-}}=2.9 \mathrm{~V}\right.$, field-of-view $(\mathrm{FOV})=25 \mu \mathrm{m})$.
The deoxidation starts at a temperature of $760^{\circ} \mathrm{C}$ with the formation of circular voids as it is the case for thicker samples (see Fig. 3(a) obtained after the increase in the temperature to $775^{\circ} \mathrm{C}$ ). In the course of the deoxidation process, the void density increases ${ }^{27}$ and leads to the coalescence of multiple circular voids. This effect causes an impressive change since deoxidation zones are no longer circular shaped as in the beginning of the deoxidation process, but exhibit a dendritic shape (Fig. 3(b)). Close to the center of the image, a blue circle marks a distortion of the image by a charging effect of the surface induced by the insulating $\mathrm{SiO}_{2}$ substrate.

The dewetting voids form at a temperature of $775^{\circ} \mathrm{C}$ (Fig. 3(c)). Directly after the formation, these voids exhibit a

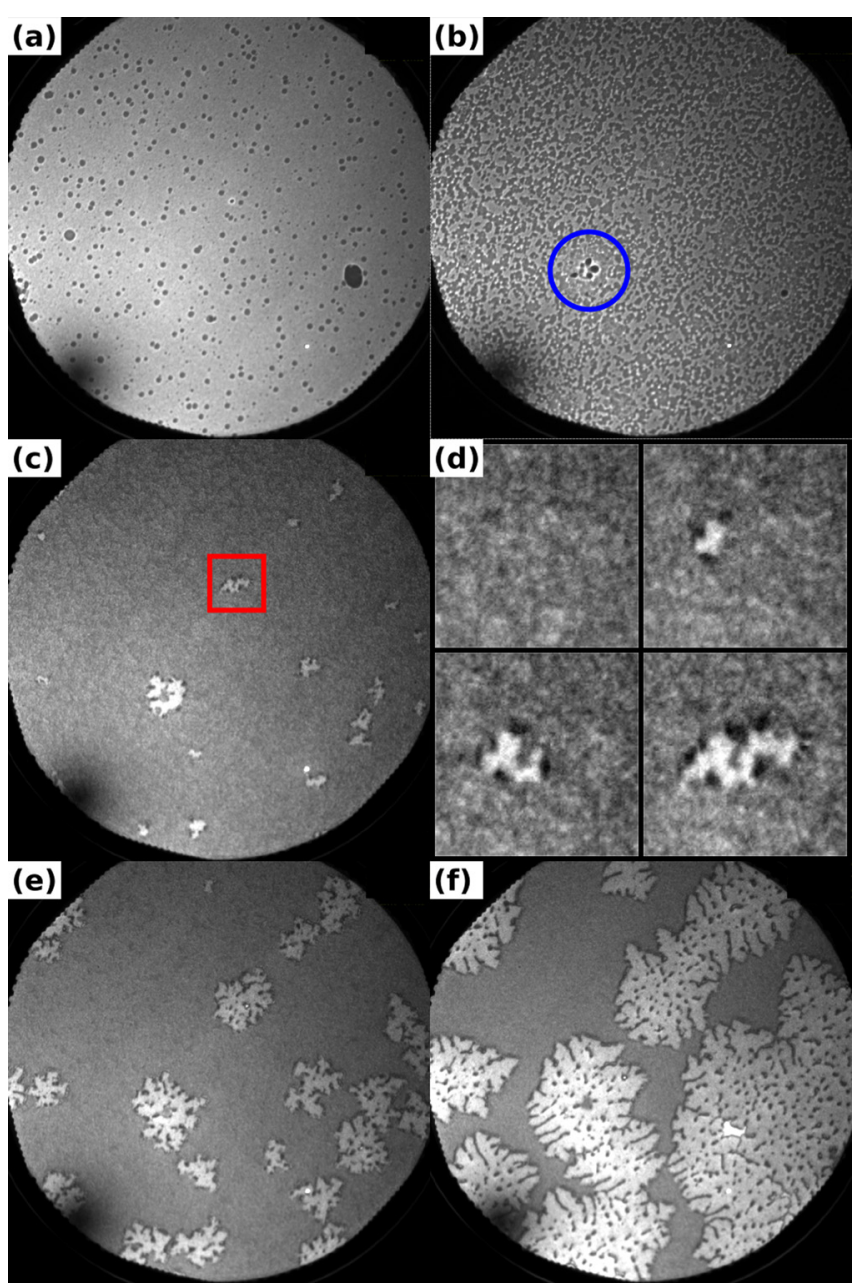

FIG. 3. Different stages of deoxidation and dewetting of a Si film with $\mathrm{h}=5.5 \mathrm{~nm}$ taken from LEEM movies showing the same position with a FOV of $25 \mu \mathrm{m}$ : (a) Initial deoxidation of the thin oxide layer with circular shaped voids, $\mathrm{Si}$ with dark, $\mathrm{SiO}_{2}$ with bright contrast $\left(E_{e^{-}}=0.9 \mathrm{~V}, 775^{\circ} \mathrm{C}, \mathrm{t}=0 \mathrm{~s}\right)$. (b) Intermediate stage of deoxidation of the thin oxide layer with dendritic shaped voids, oxide layer with dark grey, and Si film with light grey contrast. The blue circle marks a slight distortion of the image $\left(E_{e^{-}}=0.8 \mathrm{~V}\right.$, $775^{\circ} \mathrm{C}, \mathrm{t}=1010 \mathrm{~s}$ ). (c) Dendritic dewetting of the Si film (Si islands in black and BOX layer in white) while the deoxidation is still active, oxide layer with dark grey, and Si film with light grey contrast $\left(E_{e^{-}}=2.9 \mathrm{~V}, 775^{\circ} \mathrm{C}\right.$, $\mathrm{t}=870 \mathrm{~s}$ ). (d) Details from the red-marked area in (c) at different times showing the appearance and growth of a dewetting void $\left(3 \times 3 \mu \mathrm{m}^{2}\right.$, $\mathrm{t}=(410 / 560 / 720 / 870)$ s. (e) Final stage of the deoxidation and end of the dendritic dewetting $\left(E_{e^{-}}=2.9 \mathrm{~V}, 775^{\circ} \mathrm{C}, \mathrm{t}=1220 \mathrm{~s}\right)$. (f) Sample completely deoxidized. Square-shaped dewetting voids with edges in $\langle 110\rangle$ directions and formation of dewetting fingers $\left(E_{e^{-}}=2.9 \mathrm{~V}, 800^{\circ} \mathrm{C}, \mathrm{t}=1480 \mathrm{~s}\right)$. 
more or less round shape and contain one or more Si islands depending on their size (Fig. 3(d)). These islands are located close to the deoxidation front at the edge of the dewetting voids. There is no formation of dewetting fingers within this stage. As the dewetting voids grow, one can observe that some fronts are stable over a long time while others dewet very fast. This leads to a change in the shape of the dewetting voids from round to dendritic.

Close to the end of the deoxidation, an increased occurrence of $90^{\circ}$-terminated void fingers can be seen (Fig. 3(e)). This indicates the beginning of the change in the dewetting mode from dendritic to square-shaped voids with edges in $\langle 110\rangle$ orientation. As soon as the oxide layer on top of the $\mathrm{Si}$ film has disappeared, square-shaped dewetting expands as for thicker deoxidized Si films (cf. Fig. 2(b) and Fig. 3(f)).

For samples with a Si film of less than $4 \mathrm{~nm}$, the temperature necessary for the creation of dewetting voids $T_{\text {dew }}$ decreases rapidly (see Fig. 1). This implies that the deoxidation temperature of $760^{\circ} \mathrm{C}$ is already above the dewetting temperature $\left(730^{\circ} \mathrm{C}\right.$ for a Si film of $\left.3.7 \mathrm{~nm}\right)$. In Fig. 4(a), the deoxidation of this sample with a very large number of voids is imaged. The white areas are already deoxidized while the dark grey regions are still protected by the capping oxide. At the same time, fast growing elongated grey structures are visible due to the dewetting of the deoxidized regions. With a change in the imaging parameters, one can reveal these dendritic structures (white contrast in Fig. 4(b)). No change in the dewetting mode was observed in this sample: the dendritic dewetting continued until the whole sample was dewetted.

We now focus on the interpretation of these results. The driving force for Si film dewetting (i.e., the surface energy gain due to the disappearance of the Si surface and the film/ substrate interface with respect to the uncovering of the BOX surface) is irrelevant for the oxidized part of the $\mathrm{Si}$ film. It means that only deoxidized areas of the surface can trigger the Si film dewetting. For thin Si films, the deoxidation and dewetting are still well separated, and the dewetting behaves classically (square opening with fingers formation followed by beading). For ultrathin $\mathrm{Si}$ films, deoxidized areas and dewetting voids coexist. In this case, the dewetting shape is limited by the deoxidation void shapes and thus is first circular before switching to a dendritic shape when

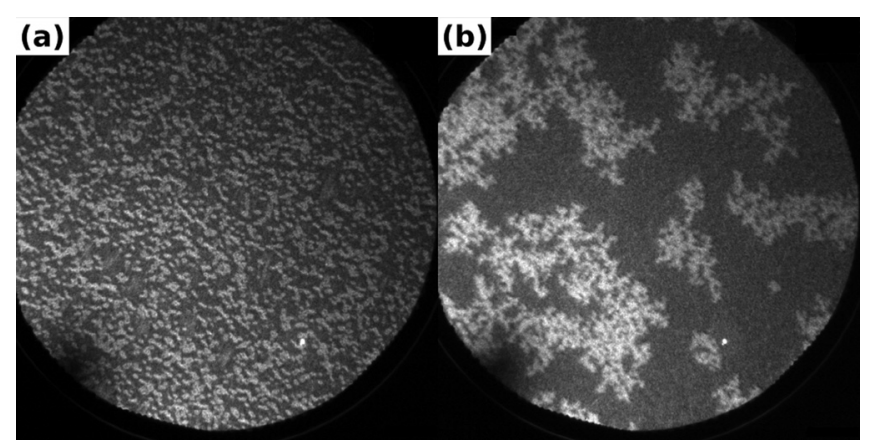

FIG. 4. Annealing of a Si film with $\mathrm{h}=3.7 \mathrm{~nm}$. (a) Slow deoxidation (oxide dark grey, Si film white contrast), whereas already large dewetted areas are visible (elongated grey structures), $\left(E_{e^{-}}=2.2 \mathrm{~V}\right.$, FOV $\left.15 \mu \mathrm{m}, 760^{\circ} \mathrm{C}\right)$. (b) Very fast dendritic dewetting with formation of Si islands directly at the dewetting front $\left(E_{e^{-}}=3.3 \mathrm{~V}\right.$, FOV $\left.25 \mu \mathrm{m}, 760^{\circ} \mathrm{C}\right)$. numerous deoxidized areas coalesce. If dewetting and deoxidation occur with similar kinetics, the deoxidation limits the dewetting during the whole process whereas if the deoxidation kinetics exceeds only slightly the dewetting kinetics, the dewetting mechanism changes from dendritic to square opening as soon as the oxidized area becomes too small to influence the dewetting. The control of the dewetting by the deoxidation is clearly evidenced in Fig. 3(d) where it can be seen that the dewetting front coincides with the deoxidized area edge giving birth to local 3D islands for mass conservation reasons. The effect of oxygen/silicon interaction on the solid-state dewetting has been already discussed for the SOI samples under an oxygen partial pressure. ${ }^{28}$ In the so-called active oxidation regime of the clean $\mathrm{Si}$ film (i.e., without the formation of an oxide layer), the inhibition of the SOI dewetting has been clearly evidenced.

In addition to the influence of the deoxidation void shape, we should expect a feedback effect. Indeed, the deoxidation mechanism is due to the formation of volatile $\mathrm{SiO}$ species by means of the reaction $\mathrm{Si}+\mathrm{SiO}_{2} \rightarrow 2 \mathrm{SiO}^{3,27}$ The deoxidation creates local depressions in the $\mathrm{Si}$ film that may act as nucleation centers for the Si film dewetting. Once the dewetting started, the $\mathrm{Si}(100)$ film voids to generate a flux of $\mathrm{Si}$ atoms on the film surface that in turn accelerates the deoxidation at the edges of the capping oxide/Si film interfaces by providing additional $\mathrm{Si}$ reactant atoms. In other words, the interplay between deoxidation and dewetting deeply affects the local shapes of both the dewetting voids and the deoxidized areas.

These mechanisms may be checked by KMC simulations. The model reported in Refs. 12, 21, 25, and 29 uses the ratio between the surface energy gain $\mathrm{E}_{S}$, the first neighbor $\mathrm{Si}-\mathrm{Si}$ interaction $\mathrm{J}\left(\mathrm{E}_{S} \mathrm{~J}\right)$, and the reduced temperature $\mathrm{k}_{B} \mathrm{~T} / \mathrm{J}$ as main ingredients. For clean $\mathrm{Si}$ films (completely deoxidized), the surface-energy-driven KMC model reproduces the key features of the dewetting experiments as shown for the initial stage of dewetting in Fig. 5(a) and in Ref. 30 for longer times where the experimental image of Fig. 2(b) is recovered. The initial KMC code has been here modified by adding an oxide cap. More precisely, two new ingredients are thus considered: (1) the dewetting cannot occur in an oxidized zone and (2) deoxidation occurs by stochastic voidopening with a distribution of void velocities corresponding to the experimental results reported by Leroy et al. ${ }^{26}$ for chemically formed oxide.

The so-obtained results are reported in Figs. 5(b)-5(d) for the slow deoxidation rate (i.e., $\mathrm{E}_{S /} \mathrm{J}=2.0$ and $\mathrm{k}_{B} \mathrm{~T} / \mathrm{J}$ $=0.4$ ). (i) The deoxidation starts in a very large number of areas (Fig. 5(b)), then (ii) dewetting stochastically starts in several deoxidized areas (Fig. 5(c)) forming isolated islands at the void edges, and (iii) void coalescence leads to a dendritic structure fitted by the dewetting zones (Fig. 5(d)). This simple KMC model is enough to reproduce all the key features of the dewetting of SOI films capped by a $\mathrm{SiO}_{2}$ layer. Note that a more realistic model should also incorporate the feedback effect to reproduce more nicely the change of the dewetting modes.

In conclusion, the transition from square-shape to dendritic dewetting geometry observed for SOI ultrathin films capped by a $\mathrm{SiO}_{2}$ oxide is due to an interplay between the 


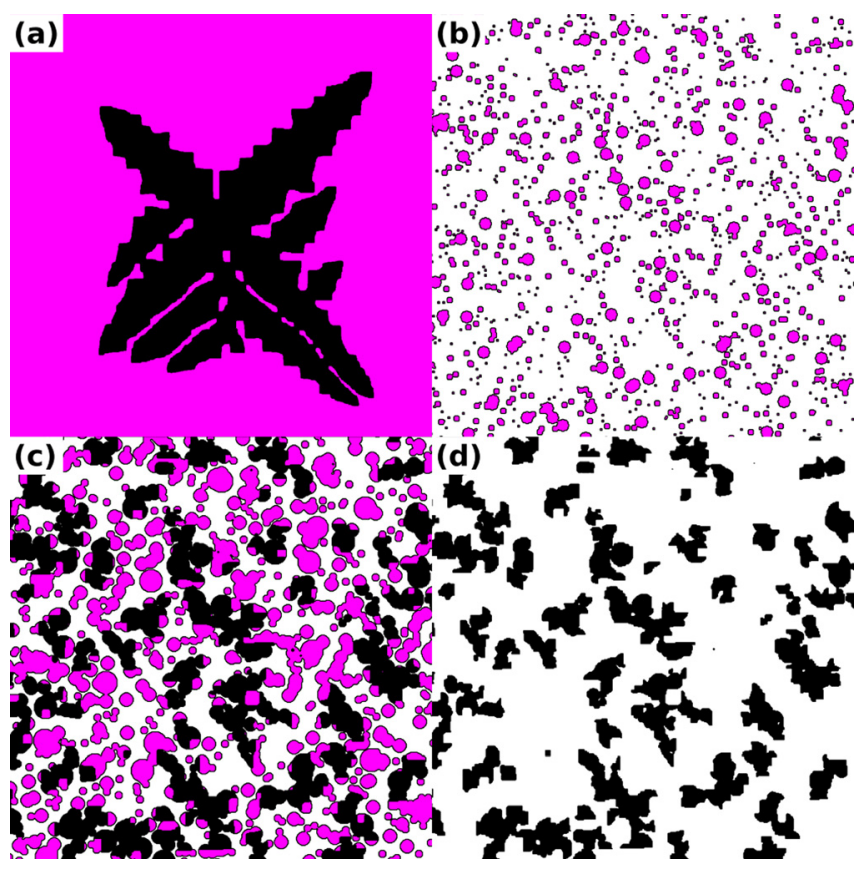

FIG. 5. KMC simulation of dewetting with $\mathrm{SiO}_{2}$ oxide cap in white, $\mathrm{Si}$ film in magenta, and BOX in black $\left(\mathrm{E}_{S} / \mathrm{J}=2.0\right.$ and $\mathrm{k}_{B} \mathrm{~T} / \mathrm{J}=0.4$, initial $\mathrm{Si}$ film thickness $=3 \mathrm{ML}$ ). (a) Dewetting without capping oxide shows squareshaped void evolution, $1000 \times 1000$ lattice. (b)-(d) Dewetting of a 3 ML-thick $\mathrm{Si}(100)$ film capped with a 1 ML-thick oxide and a slow deoxidation rate $(500 \times 500$ lattice): (b) Initial stage with opening of circular deoxidation voids. (c) Late stage with dendritic dewetting morphologies and $\mathrm{Si}$ islands forming on the edge of the dewetting voids. (d) Same as (c) with only the dewetted areas visible (Si film and oxide cap in white).

surface deoxidation (that occurs at a constant temperature) and the dewetting process (whose temperature depends on the thickness of the film) and probably not to a spinodal, stress, or wetting potential effects. More generally, it has to be considered that this interplay has an impact on a larger variety of phenomena and materials provided that the dewetting and deoxidation temperatures are close to each other. As it is demonstrated for the case of SOI, the self-organisation of stationary $3 \mathrm{D}$ islands is affected. The usefulness of these results extends wider to dynamic phenomena as self-running droplets where the starting material has to be deoxidized and dewetted as for self-propelled AuSi droplets on $\mathrm{Si}(111)^{31}$ or $\mathrm{Ga}$ droplets on $\mathrm{GaAs}(001){ }^{32}$

The authors thank O. Pierre-Louis for fruitful discussions, F. Bedu and I. Ozerov for sample preparation at PLANETE (CNano PACA), I. Berbezier, M. Abbarchi (IM2NP), and
J.-C. Barbé (LETI) for providing us SOI samples. We acknowledge ANR-13-BS04-0004-02 Grant LOTUS for the financial support.

${ }^{1}$ C. Thompson, Annu. Rev. Matter. Res. 30, 159 (2000).

${ }^{2}$ C. Thompson, Annu. Rev. Matter. Res. 42, 399 (2012).

${ }^{3}$ F. Leroy, L. Borowik, F. Cheynis, Y. Almodori, S. Curiotto, M. Trautmann, J. Barbe, and P. Müller, Surf. Sci. Rep. 71, 391 (2016).

${ }^{4}$ G. Capellini, G. Ciasca, M. de Seta, A. Notargiacomo, F. Evangeslisy, and M. Nardone, J. Appl. Phys. 105, 093525 (2009).

${ }^{5}$ B. Legrand, V. Agache, T. Melin, J. Nys, V. Senez, and D. Stievenard, J. Appl. Phys. 91, 106 (2002).

${ }^{6}$ R. Nuryadi, Y. Ishikawa, Y. Ono, and M. Tabe, J. Vac. Sci. Technol. B 20, 167 (2002).

${ }^{7}$ M. Yoshino, H. Osawa, and A. Yamanaka, J. Manuf. Processes 14, 478 (2012).

${ }^{8}$ Y. Wakayama, T. Tagami, and S. Tanaka, J. Appl. Phys. 85, 8492 (1999).

${ }^{9}$ M. Naffouti, T. David, A. Benkouider, L. Favre, A. Ronda, I. Berbezier, S. Bidault, N. Bonod, and M. Abbarchi, Nanoscale 8, 2844 (2016).

${ }^{10}$ F. Cheynis, F. Leroy, and P. Müller, C. R. Phys. 14, 578 (2013).

${ }^{11}$ A. Chame and O. Pierre-Louis, C. R. Phys. 14, 553 (2013).

${ }^{12}$ O. Pierre-Louis, A. Chame, and Y. Saito, Phys. Rev. Lett. 99, 136101 (2007).

${ }^{13}$ J.-Y. Kwon, T. Yoon, K. B. Kim, and S. H. Min, J. Appl. Phys. 93, 3270 (2003).

${ }^{14}$ Z. Burhanudin, R. Nuryadi, Y. Ishikawa, M. Tabe, and Y. Ono, Thin solid films 508, 235 (2006).

${ }^{15}$ K. Thürmer, E. D. Willams, and J. E. Reutt-Robey, Phys. Rev. B 68 , 155423 (2003).

${ }^{16}$ H. Galinski, T. Ryll, P. Elser, L. Rupp, A. Bieberle-Hutter, and L. Gauckler, Phys. Rev. B 82, 235415 (2010).

${ }^{17}$ R. Xie, A. Karim, J. Douglas, C. Han, and R. Weiss, Phys. Rev. Lett. 81, 1251 (1998).

${ }^{18}$ R. Seemann, S. Herminghaus, and K. Jacobs, Phys. Rev. Lett. 86, 5534 (2001).

${ }^{19}$ O. Pierre-Louis, Prog. Cryst. Growth Charact. Mater. 62, 177 (2016).

${ }^{20}$ J. Petersen and S. Mayr, J. Appl. Phys. 103, 023520 (2008).

${ }^{21}$ E. Bussmann, F. Cheynis, F. Leroy, and P. Müller, IOP Conf. Ser.: Mater. Sci. Eng. 12, 012016 (2010).

${ }^{22}$ E. Bauer, Rep. Prog. Phys. 57, 895 (1994).

${ }^{23}$ J. Cazaux, J. Appl. Phys. 111, 064903 (2012).

${ }^{24}$ D. T. Danielson, D. K. Sparacin, J. Michel, and L. C. Kimerling, J. Appl. Phys. 100, 083507 (2006).

${ }^{25}$ F. Cheynis, E. Bussmann, F. Leroy, T. Passanante, and P. Müller, Phys. Rev. B 84, 245439 (2011)

${ }^{26}$ F. Leroy, T. Passanante, F. Cheynis, S. Curiotto, E. B. Bussmann, and P. Müller, Appl. Phys. Lett. 108, 111601 (2016).

${ }^{27} \mathrm{H}$. Hibino, M. Uematsu, and Y. Watanabe, J. Appl. Phys. 100, 113519 (2006).

${ }^{28}$ S. Curiotto, F. Leroy, F. Cheynis, and P. Müller, Appl. Phys. Lett. 104, 061603 (2014).

${ }^{29}$ O. Pierre-Louis, A. Chame, and Y. Saito, Phys. Rev. Lett. 103, 195501 (2009).

${ }^{30}$ E. Bussmann, F. Cheynis, F. Leroy, P. Müller, and O. Pierre-Louis, New J. Phys. 13, 043017 (2011).

${ }^{31}$ S. Curiotto, F. Leroy, F. Cheynis, and P. Müller, Surf. Sci. 632, 1 (2015).

${ }^{32}$ J. Tersoff, D. E. Jesson, and W. X. Tang, Science 324, 236 (2009). 